\title{
Estimating traveltimes and groundwater flow patterns using 3D time-lapse crosshole ERT imaging of electrical resistivity fluctuations induced by infiltrating river water
}

\author{
Ilaria Coscia ${ }^{1}$, Niklas Linde ${ }^{2}$, Stewart Greenhalgh ${ }^{3}$, Tobias Vogt ${ }^{4}$, and Alan Green ${ }^{1}$
}

\begin{abstract}
The infiltration of river water into aquifers is of high relevance to drinking-water production and is a key driver of biogeochemical processes in the hyporheic and riparian zone, but the distribution and quantification of the infiltrating water are difficult to determine using conventional hydrological methods (e.g., borehole logging and tracer tests). By time-lapse inverting crosshole ERT (electrical resistivity tomography) monitoring data, we imaged groundwater flow patterns driven by river water infiltrating a perialpine gravel aquifer in northeastern Switzerland. This was possible because the electrical resistivity of the infiltrating water changed during rainfall-runoff events. Our time-lapse resistivity models indicated rather complex flow
\end{abstract}

patterns as a result of spatially heterogeneous bank filtration and aquifer heterogeneity. The upper part of the aquifer was most affected by the river infiltrate, and the highest groundwater velocities and possible preferential flow occurred at shallow to intermediate depths. Time series of the reconstructed resistivity models matched groundwater electrical resistivity data recorded on borehole loggers in the upper and middle parts of the aquifer, whereas the resistivity models displayed smaller variations and delayed responses with respect to the logging data in the lower part. This study demonstrated that crosshole ERT monitoring of natural electrical resistivity variations of river infiltrate could be used to image and quantify 3D bank filtration and aquifer dynamics at a high spatial resolution.

\section{INTRODUCTION}

Pumping wells close to many rivers produce large quantities of drinking water (e.g., $40 \%$ of Swiss drinking water is produced by such wells; BUWAL, 2004). In addition, infiltrating river water delivers nutrients to the hyporheic and riparian zones (Triska et al., 1993). Maintaining adequate water supply and quality is clearly essential for both human survival and the biodiversity of many terrestrial and aquatic ecosystems. An understanding and quantification of infiltration rates and associated groundwater flow and transport mechanisms are necessary for effective water management and protection. The groundwater residence times after river-water infiltration for drinking water production are legally imposed in many countries (e.g., BUWAL, 2004), such that reliable methods are needed to determine these times. This is challenging due to the large spatial and temporal variations of the underlying processes (Fleckenstein et al., 2006). Furthermore, improved understanding of hyporheic flow dynamics will help to resolve other questions, such as the potential of the surface water groundwater mixing region to attenuate pollutants (Schwarzenbach and Westall, 1981) or enhance denitrification (Ranalli and Macalady, 2010).

Conventional hydrological field methods for studying interactions between river water and groundwater (Kalbus et al., 2006) usually provide data representing limited support volumes (e.g., from borehole logging) or data with inadequate spatial resolution (e.g., from tracer tests), which makes it difficult to gain a detailed understanding of groundwater flow patterns in the vicinity of rivers. In this regard, geophysical techniques offer a valuable complement

Manuscript received by the Editor 3 September 2011; revised manuscript received 21 December 2011; published online 18 June 2012

'ETH Zürich, Institute of Geophysics, Zürich, Switzerland. E-mail: coscia.ilaria@gmail.com; alan@aug.ig.erdw.ethz.ch.

${ }^{2}$ University of Lausanne, Institute of Geophysics, Lausanne, Switzerland. E-mail: niklas.linde@unil.ch.

${ }^{3}$ ETH Zürich, Institute of Geophysics, Zürich, Switzerland, and University of Adelaide, Department of Physics, Adelaide, Australia. E-mail: greenhalgh @aug ig.erdw.ethz.ch.

${ }^{4}$ Eawag - Swiss Federal Institute of Aquatic Science and Technology, Dübendorf, Switzerland. E-mail: tobias.vogt@eawag.ch.

(C) 2012 Society of Exploration Geophysicists. All rights reserved. 
to hydrological methods. In addition to being noninvasive (e.g., airborne and surface surveys) or minimally invasive (e.g., borehole and crosshole surveys), geophysical techniques supply information that partially fills the gaps in scale and resolution associated with traditional hydrological investigations (Hubbard and Rubin, 2000). Geophysical techniques have provided useful information for building conceptual models that improve our understanding of exchange processes between river water and groundwater at scales ranging from meters (Nyquist et al., 2008) to kilometers (Slater et al., 2010). Numerous investigations have also demonstrated the efficacy of geophysical methods in analyzing hyporheic exchange mechanisms (Acworth and Dasey, 2003; Singha et al., 2008; Ward et al., 2010; Cardenas and Markowski, 2011) and in exploring the influence of surface water salinity or pollution on groundwater quality (Slater and Sandberg, 2000; Fàlgas et al., 2009; de Franco et al., 2009; Nguyen et al., 2009; Ogilvy et al., 2009; Viezzoli et al., 2010; Hatch et al., 2010; Kirkegaard et al., 2011). Electrical and electromagnetic methods have been the most popular geophysical techniques in studies related to surface water groundwater interactions. A major reason for their popularity is that electrical resistivity is closely linked to porosity, pore structure, water content, and pore fluid salinity through relatively well-understood petrophysical relationships (Lesmes and Friedman, 2005). The current practice and future trends of electrical resistivity tomography (ERT) for monitoring purposes were recently showcased and explored at

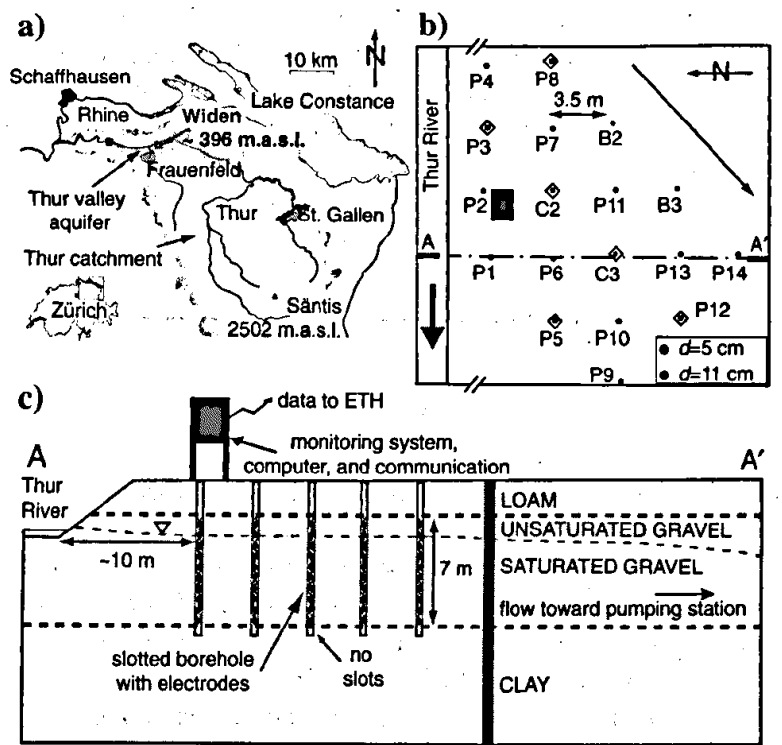

Figure 1. (a) Location of the Thur River catchment, Thur valley aquifer, and the Widen study site in northeastem Switzerland (modified from a figure prepared by the Swiss Federal Office of Topography). (b) Plan view of part of the Widen site showing borehole positions with respect to the river. The black arrow in the upper right comer represents the groundwater flow direction under low water conditions estimated from the hydraulic heads measured by loggers in the boreholes. The boreholes containing groundwater loggers are marked with diamonds. Note the orientation of this diagram. (c) Vertical section $\mathrm{A}^{\prime} \mathrm{A}$ through the study site (see location in b) showing electrode installations, stratigraphy, groundwater level, and riverwater flow direction. The average elevation of the flat ground surface is $396.26 \mathrm{~m}$. The elevation of the water table ranges from 391.9 to $393.0 \mathrm{~m}$ (dependent on river stage). the First International Workshop on Geoelectrical Monitoring, held in Vienna, from 30 November to 2 December 2011. Applications covered not only hydrology projects, but also geothermal, $\mathrm{CO}_{2}$ sequestration, permafrost monitoring, civil engineering, and contaminant monitoring.

Tracking the effects of natural stimuli has been the mòst appropriate means for obtaining measurable hydrological or geophysical responses in large-scale surface-water-groundwater studies (e.g., those associated with seawater intrusion, large rivers, or catchments; Yeh et al., 2008). Several studies have demonstrated the advantages and efficacy of using natural fluctuations of state variables (e.g., temperature, electrical resistivity, water height, or isotope concentrations) within river-aquifer systems. For example, temperature and electrical resistivity time series of river water and groundwater have been used to calculate traveltimes of infiltrating river water in groundwater (Sheets et al., 2002; Hoehn and Cirpka, 2006; Cirpka et al., 2007; Constantz, 2008; Vogt et al., 2010). However, most studies have been limited to a few observation-well measurements that may not be representative due to the inherent heterogeneity of, for example, alpine and perialpine fluvial deposits (Huggenberger et al., 1998).

In this paper, we investigate to what extent 3D crosshole ERT monitoring of temporally varying electrical resistivity of infiltrating river water can be used to image how the river water propagates into an adjacent aquifer. We rely on ERT data acquired during and subsequent to a rainfall-runoff event in the vicinity of a perialpine gravel aquifer in northeastem Switzerland. Our aim is to assess in detail the arrival times and transport of the infiltrating river water throughout the study site, which cannot be resolved using point measurements in observation wells alone.

Coscia et al. (2011) describe the dense crosshole ERT monitoring network at our study site, demonstrated the sensitivity of the recorded monitoring data to groundwater electrical resistivity and groundwater height (water table level) fluctuations, and provided a 3D electrical stratigraphy model of the region. In addition, Coscia et al. (2012) present filtering methods for minimizing the effects of temperature and groundwater height fluctuations on the apparent resistivity data. The present contribution builds on these previous studies by focusing on the imaging and quantification of groundwater dynamics.

After reviewing essential details of our study site and data acquisition strategy, we summarize how the data were processed using the methods developed by Coscia et al. (2012). We then briefly describe the time-lapse inversion scheme we use, together with the results of applying this scheme to the filtered crosshole ERT monitoring data. By analyzing time series of electrical resistivity values extracted from the inversion models at chosen locations, we then obtain information about the groundwater flow arrival-time distribution, its speeds and directions, and mixing processes.

\section{STUDY SITE AND DATA ACQUISITION}

At our study site in northeastern Switzerland (Figure la), the Thur River is constantly infiltrating a highly permeable gravel aquifer (Cirpka et al., 2007). Detailed investigations reveal that the 7-m-thick aquifer is overlain by a 3-m-thick surface layer of loam and underlain by a lacustrine clay aquitard (Figure 1c; Diem et al., 2010; Doetsch et al., 2010a; Klotzsche et al., 2010; Coscia et al., 2011). The fluvial sediments of the aquifer were deposited after the last glaciation at the beginning of the Holocene (Naef and Frank, 
2009). Gravel is the dominant constituent, followed by sand and silt. According to the USCS classification of sediments (SN670008a, 1997), the aquifer can be defined as GM (silty gravel).

Multilevel slug tests suggest that the hydraulic conductivity of the aquifer has a geometric mean of $4.2 \times 10^{-3} \mathrm{~m} / \mathrm{s}$ (Diem et al., 2010). It appears to be more permeable at shallow to intermediate depths than at greater depths. The upper $\sim 1 \mathrm{~m}$ of the aquifer is unsaturated under normal discharge conditions of $\sim 47 \mathrm{~m}^{3} / \mathrm{s}$ (www .hydrodaten.admin.ch), but fully saturated under high discharge conditions of $>500 \mathrm{~m}^{3} / \mathrm{s}$ (Diem et al., 2010). According to catchment modeling (Baumann et al., 2009), the groundwater close to the river flows in a $40^{\circ}-50^{\circ}$ direction away from the westerly flowing river, toward the southwest. Cirpka et al. (2007) identify a stratified groundwater body with a local flow component at the top associated with the infiltrating river water and a regional flow component at the bottom of the aquifer. A horizontal pumping well located about $200 \mathrm{~m}$ inland from the study site produces approximately $9000 \mathrm{~m}^{3} / \mathrm{d}$ of water.

For our experiments, eighteen $\sim 12$-m-deep boreholes that are located close to the river were utilized (Figure 1b). Each borehole is slotted and equipped with a geoelectric cable and ten electrodes spaced at $0.7 \mathrm{~m}$ intervals through the gravel aquifer. The cables are connected to a flood-proof hut, where the ERT recording device and a computer are installed. The latter controls the measurement sequence, stores the data, and allows the entire monitoring system to be remotely checked and the data downloaded (see Figure $1 \mathrm{~b}$ and $1 \mathrm{c}$ ). Fourteen sensors and integrated data loggers are installed in selected boreholes (marked by diamonds in Figure $1 \mathrm{~b}$ ) at depths of $\sim 4.6, \sim 6.6$, and $\sim 8.6 \mathrm{~m}$. The sensors provide continuous measurements of water electrical resistivity, hydraulic pressure (which is converted to groundwater height), and temperature. Errors of single measurements according to the manufacturer's manual are $\pm 2 \%$ for resistivity, $\pm 0.1 \%$ for pressure, and $\pm 0.25^{\circ} \mathrm{K}$ for temperature. The same types of sensor record data at a river gauging station $\sim 50 \mathrm{~m}$ downstream of the boreholes.

We employed a circulating fully 3D ERT collection scheme that yielded $\sim 15,500$ data values every $7 \mathrm{~h}$. The ERT monitoring started in March 2009 and terminated in December 2010. Despite various technical problems, more than one-year's worth of apparent resistivity data were acquired, with the longest continuous period of measurements covering $\sim 3$ months. Further details on the site, instrumentation, installation, and the ERT recording strategy are given by Coscia et al. (2011). The research program was designed to determine temporal and spatial variations in the true (or bulk) subsurface resistivity distribution from the apparent resistivity time-lapse measurements. This, in turn, was used to investigate groundwater transport processes and elucidate aquifer dynamics by exploiting natural variations in the resistivity of infiltrating river water.

\section{PROCESSING THE CROSSHOLE ERT DATA}

Our time series of raw ERT apparent resistivities $\left(\rho_{a}^{\text {raw }}\right)$ are affected by variations of groundwater resistivity, groundwater height, and groundwater temperature $\left(\rho^{\mathrm{gw}}, h^{\mathrm{gw}}\right.$, and $\left.T^{\mathrm{gw}}\right)$, which, in turn, are influenced by fluctuations in river water resistivity, river water height (or river stage), and river water temperature $\left(\rho^{\mathrm{rw}}, h^{\mathrm{rw}}\right.$, and $\left.T^{\mathrm{Tw}}\right)$. The processing that we apply to the various time series is described in detail by Coscia et al. (2012).

\section{Accounting for temperature effects}

We begin by filtering out variations in the different time series at periods smaller than the $\sim 7 \mathrm{~h}$ required to acquire a single complete ERT apparent resistivity data set. Subsequently, we correct $\rho^{\mathrm{gw}}$ and $\rho^{\mathrm{rw}}$ to the yearly median values of groundwater and river water temperature using a method described in ISO7888 (1985). Seasonal trends in river temperature $T^{\mathrm{rw}}$ are responsible for maximum changes of $\sim 16^{\circ} \mathrm{C}$ in groundwater temperature $T^{\mathrm{gw}}$ and an associated $\sim 29 \%$ variation of $\rho^{\mathrm{gw}}$. To remove the effects of seasonal temperature trends on $\rho_{a}^{\text {raw }}$, we apply a linear regression procedure that minimizes the correlation between output apparent resistivities $\rho_{a}$ and variations in groundwater temperature $T^{\mathrm{gw}}$. In this way, we obtain temperature-detrended $\rho_{a}$ values that mostly depend on $\rho^{\mathrm{gw}}$ and $h^{\mathrm{gw}}$.

\section{Accounting for water height effects}

Rapid increases in $\rho^{\mathrm{rw}}$ are caused by the dilution of total dissolved solids in the river water after rainfall events, which, after a certain time delay (as the river water infiltrates the aquifer), generate increases in $\rho^{\mathrm{gw}}$. Maximum effects of the dilution process on $\rho^{\mathrm{gw}}$ are typically on the order of $10 \%-15 \%$ with respect to values under normal flow conditions, which translate to similar relative changes of the aquifer's bulk resistivity $\rho$. Increasing discharges following rainfall also create significant increases in river-water height, which induce near-instantaneous increases in groundwater height. These increases affect the ERT apparent resistivity data due to changes in the relative proportions of the unsaturated (electrically more resistive) and saturated (electrically more conductive) zones of the aquifer. A rise in groundwater height causes a decrease in apparent resistivity for most, but not all, electrode configurations. Thus, variations in $h^{\mathrm{rw}}$ and $h^{\mathrm{gw}}$ usually have the opposite effect to variations in $\rho^{\mathrm{rw}}$ and $\rho^{\mathrm{gw}}$ on the ERT data, with the water-height components tending to partially or totally mask the water-resistivity components during periods of large water-height fluctuations (e.g., $>0.5 \mathrm{~m}$ with respect to normal conditions).

Before we time-lapse invert the apparent resistivity data for variations in the aquifer's bulk resistivity and, by inference, variations in groundwater resistivity, we need to account for the effects of the water-height fluctuations. In principle, this could be achieved by either (1) including the water-height fluctuations as known parameters in the inversion process, (2) numerically modeling the effects of the fluctuations and subtracting them from $\rho_{a}$ before inversion, or (3) estimating the effects of the fluctuations from the various recorded time series and again subtracting them from $\rho_{a}$ before inversion. Of these three possibilities, (3) is the most practical. Our approach, detailed by Coscia et al. (2012), is based on the assumption that temporal variations of $\rho_{a}$ for each electrode configuration can be described as a superposition of two contributions:

1) river water resistivity time series convolved with a smoothly varying causal filter function of finite length

2) linear and quadratic representations of water-height variation multiplied by appropriate sensitivity factors.

The quadratic term in contribution (2) is required to account for a slightly nonlinear relationship between apparent resistivity and groundwater height, which we found in a systematic numerical modeling study of simple 1D models with varying thicknesses and resistivities of the saturated zone (Coscia et al., 2012). Because 
each of the $\sim 15,500$ electrode configurations yields a different $\rho_{a}$ time series, they each require a uniquely defined filter function and pair of sensitivity factors. The coefficients of each filter function and the sensitivity factors are estimated by deconvolving the temperature-detrended apparent resistivities (output data) with the riverwater resistivities and heights (input data) for a specified calibration period, which amounts to solving a linear inverse problem for each electrode configuration. For this study, the calibration period is shown in Figure 2.

To obtain filtered apparent resistivity time series $\rho_{a}^{f}$ dominated by the aquifer's bulk resistivity, it is simply necessary to subtract contribution (2) from $\rho_{a}$. Figure 2a shows $\rho_{a}$ and $\rho_{a}^{f}$ values for a typical ERT configuration that is strongly affected by variations in the water height, which is shown in Figure 2c. The quantities plotted in Figure $2 \mathrm{a}$ are changes in the apparent resistivities relative to the apparent resistivities at the onsets of the displayed time series $\delta \rho_{a}$ and $\delta \rho_{a}^{f}$. Note the pronounced anticorrelation between the $\delta \rho_{a}$ and the $h^{\mathrm{rw}}$ and $h^{\mathrm{gw}}$ time series. The effectiveness of the filtering procedure is evaluated in detail by Coscia et al. (2012), but can be appreciated by observing the high correlation between $\delta \rho_{a}^{f}$ and $\rho^{\mathrm{gw}}$ (Figure 2b). In the following sections, times are expressed in days from the beginning of the time-lapse inversion period (Figure 2), chosen to be just before the first strong variations in water height.

\section{Resampling and editing the data}

Because of the fast rainfall-runoff dynamics and the high flow velocities in the gravel aquifer relative to the $\sim 7 \mathrm{~h}$ needed to record each ERT data set, the apparent resistivities acquired during a single acquisition period did not reflect a snapshot of the groundwater conditions; inverting these data could have resulted in temporal
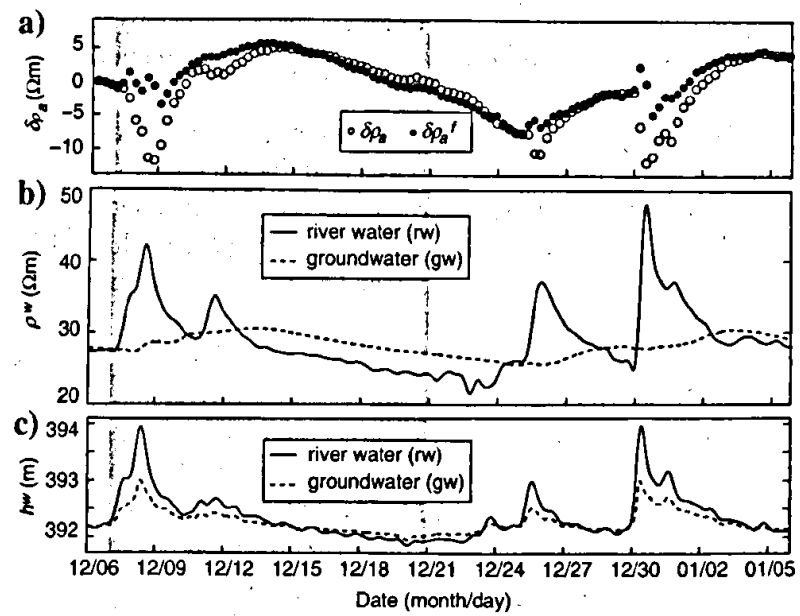

Figure 2. (a) Variations in unfiltered and filtered apparent resistivity $\delta \rho_{a}$ and $\delta \rho_{a}^{J}$ (values are relative to apparent resistivities at the beginning of the calibration period) for one example electrode configuration out of the 15,500 measured ones during the calibration period 6/12/09-6/01/10. (b) Resistivity $\rho^{\mathrm{w}}$ of river water (rw) and groundwater (gw), the latter measured in borehole P3 (see location in Figure $1 \mathrm{~b}$ ) at $\sim 6.6-\mathrm{m}$ depth. (c) River water and groundwater heights $h^{\text {rw }}$ and $h^{\text {gw }}$ during the calibration period. Filter coefficients used to estimate $\rho_{a}^{f}$ are based on data collected over the entire displayed calibration period. The time-lapse inversion period is marked in dark gray. smearing of the time-lapse inversion images (Day-Lewis et al. 2003). To minimize this effect, the smoothly varying $\rho_{a}^{f}$ data for each electrode configuration were resampled to the same equally spaced times using spline interpolation. A consistent editing procedure to eliminate potentially low quality $\rho_{a}^{f}$ data was our final step prior to the time-lapse inversions (see Coscia et al. [2012] for details). After this selection stage, we had $\sim 11,000 \rho_{a}^{f}$ values for each of 54 data sets (time frames) spaced at $\sim 7 \mathrm{~h}$ intervals.

\section{TIME-LAPSE INVERSION OF ERT DATA SETS}

\section{Forward and inverse modeling}

The ERT inversions are performed using the open-source finiteelement modeling and inversion codes of the Gimli library (www .resistivity.net; Günther et al., 2006; Rücker et al., 2006), which uses unstructured meshes created with the Tetgen software package (http://tetgen.berlios.de). The unstructured mesh allows 3D topography and internal boundaries to be represented in a flexible manner. The parameter mesh is built to represent the geometry of the inversion domain. Based on this mesh, refined meshes are created for the forward calculations (Rücker et al., 2006). We define separate inversion regions across which model regularization is disconnected; for each region we assign different inversion parameter values (Table 1; Günther et al., 2006). This decoupling is important to avoid smearing associated with the relatively resistive gravel aquifer being in contact with the underlying conductive clay aquitard (Coscia et al., 2011).

The time-lapse inversion is performed using an extended formulation of the ratio approach of Daily et al. (1992), in which we invert

$$
\log _{10}\left(\frac{\rho_{a, t}^{f}}{\rho_{a, 0}^{f}} g\left(m_{\mathrm{bk}}\right)\right),
$$

where $\rho_{a, t}^{f}$ are the temperature-detrended, water-height-corrected apparent resistivities at time $t, \rho_{a, 0}^{f}$ are the apparent resistivities at the beginning of the time-lapse period $t=0$, and $g\left(m_{\mathrm{bk}}\right)$ are the computed apparent resistivities for the background model obtained by inverting $\rho_{a, 0}^{f}$. The original formulation assumed $g\left(m_{\mathrm{mk}}\right)$ to be constant, corresponding to a uniform resistivity earth. The problem with this is that the sensitivity matrix will be inappropriate if there is significant heterogeneity in the resistivity. Our modified approach accommodates this, and is more tolerant of the nonlinearity of the inverse problem. The error models are adapted iteratively using robust data reweighting (Claerbout and Muir, 1973). We also carried out inversions of the same data using the time-lapse difference approach of LaBrecque and Yang (2001) and obtained very similar results to the ratio method. These approaches, as opposed to independent inversions at each time frame, are intended to mitigate the effects of systematic (static) and numerical errors, which can be much larger than the random measurement errors. This is especially important when the subsurface resistivity variations between each measurement phase are quite small. Nenna et al. (2011) recently attempted to combat the lack of prior knowledge of subsurface properties and the limited information about data noise. They applied an extended Kalman filtering approach to invert 2D ERT data while accounting for changes in the physical state of the system. It incorporates knowledge acquired from all previous time steps into the estimation of parameters at the current time step. This is a form of temporal regularization intended to minimize 
imaging artifacts, but it requires extremely high sampling rates relative to the expected rate of change in the monitored physical system.

The various time-lapse images obtained with any of the above three schemes are computed and analyzed under the assumption that the subsurface resistivities do not change during the time over which one complete set of apparent resistivity measurements are made. We ensured this by resampling the smoothly varying apparent resistivities at exactly the same time for each configuration (see previous section). The alternative would be to perform a 4D inversion of the monitoring data over the dynamically changing earth model (see Kim et al, 2009). Because the temporal regularization using such an approach can lead to inversion artifacts, Karaoulis et al. (2011) have recently proposed an active time-constrained (ATC) 2D resistivity inversion scheme, in which the temporal regularization is allowed to vary with time. It requires a threshold to characterize the significance of the observed resistivity changes with time, and this depends strongly on the data. Further testing and adaptation to 3D is required. Importantly for our study, the final images obtained by applying the new active time-constrained technique to both synthetic and real data were only marginally better in the region of interest than ratio images from difference inversions (Karoulis et al., 2011).

For the particular experiment described in the present study, the time constants of the dynamic infiltration process (and hence the resistivity changes) are not so short relative to the acquisition time (seven hours) for each measurement phase, the signal-to-noise $(\mathrm{S} / \mathrm{N})$ levels are quite low and the overall apparent resistivity anomalies are quite large. Therefore, the ratio method following filtering and resampling of the apparent resistivities is an appropriate approach.

\section{TIME-LAPSE INVERSIONS OF A RAINFALL-RUNOFF EVENT}

\section{The rainfall-runoff event}

The ERT time-lapse inversion procedure was applied to the $54 \rho_{a}^{f}$ data sets acquired during the 15 days starting on 7 December 2009. This corresponded to the dark gray area in Figure 2a of the calibration period used to estimate the filter functions and sensitivity factors. At the beginning of the time-lapse inversion period, the hydrological conditions were stable, $h^{\mathrm{gw}}$ was $392.2 \mathrm{masl}$, and $\rho^{\mathrm{gW}}$ varied (according to the position of the borehole loggers) between 26.9 and $27.8 \Omega \mathrm{m}$ for the yearly median groundwater reference temperature. During the time-lapse period, $h^{\mathrm{gw}}$ varied by a maximum of $0.8 \mathrm{~m}$ (dashed line in Figure $2 \mathrm{c}$ ) and $\rho^{\mathrm{gw}}$ varied by a maximum of $2.4 \Omega \mathrm{m}$ (dashed line in Figure $2 \mathrm{~b}$ ), which corresponded to an increase of $\sim 10 \%$ with respect to the background values.

\section{Time-lapse inversion of the studied event}

For the ERT modeling, we assumed that the surface of the installation field was planar and horizontal at an altitude of 396.26 masl, corresponding to the average ground elevation measured at the eighteen boreholes (maximum difference $\pm 0.25 \mathrm{~m}$ ), whereas the riverbank was taken to be planar and northward dipping at $\sim 40^{\circ}$ (Figure 1c; Coscia et al., 2011). The forward model domain had primary and secondary meshes of $\sim 86,800$ and $\sim 694,000$ elements, respectively. The inversion model domain was a $\sim 67,400$ element subset of the forward model primary mesh.

The main geological interfaces (i.e., the loam-gravel and gravelclay boundaries) delineated the separate inversion regions in the initial model. The coordinates of these slightly undulating interfaces were determined from information provided by drill cores and geophysical logs in each borehole. The interface between the saturated and unsaturated gravel aquifer was defined by the groundwater height at the beginning of the time-lapse inversion period. Regularization was decoupled in the inversion across the main regions to prevent artifacts (see Coscia et al., 2011). After several inversion tests, we decided not to explicitly include the boreholes as separate inversion regions in the time-lapse computations. The borehole fluid effect described by Doetsch et al. (2010b) at the same field site is important for standard electrode configurations (AM-BN or ABMN) operating between two closely spaced boreholes, but is only of minor importance for our nonstandard circulating 3D ERT configurations (see also Coscia et al., 2011, 2012), which for each measurement uses electrodes in three different boreholes. Moreover, the effect is generally less important in time-lapse inversions because, for each electrode configuration, it acts similarly on each time-lapse measurement and such systematic errors almost cancel when inverting differences or ratios. In addition, the roughness operator used to regularize the inversion (Günther et al., 2006) does not account for variations in the mesh size. This results in reduced regularization where the mesh elements are small, such that the smoothing constraints are effectively weaker close to the boreholes. Consequently, when including boreholes in the parameterization and using this type of regularization in time-lapse inversions, erroneously strong resistivity variations can appear near the boreholes and erroneously small variations can be imaged in between the boreholes.

We used a value of 30,000 for the initial regularization strength (i.e., the weighting factor $\lambda$ that determines the trade-off between the data misfit term and the model roughness penalty term in the objective function) for all regions of the gravel aquifer. It was

Table 1. Inversion parameters used for each region of the time-lapse inversion model.

\begin{tabular}{lccc}
\hline Region & Regularization type & $\begin{array}{c}\text { Scaling factor } n \text { for the } \\
\text { regularization parameter } \lambda\end{array}$ & $\begin{array}{c}\because \\
\text { Bounding values } \\
\rho_{\text {lower }}-\rho_{\text {upper }}(\Omega \mathrm{m})\end{array}$ \\
\hline Loam & Damping & 10 & $10-2000$ \\
Unsaturated gravel aquifer & Isotropic smoothing & 1 & $50-2000$ \\
Saturated gravel aquifer & Isotropic smoothing & 1 & $10-1000$ \\
Aquitard (Clay layer) & Damping & 10 & $5-45$ \\
\hline
\end{tabular}


successively decreased at each iteration step by a factor of 0.5 . Table 1 lists the type of regularization adopted for the different inversion regions, the $n$ scaling factors used to enhance or reduce (in a relative sense) the regularization strength $\lambda$ within each region, and the lower and upper permissible bounds of the model parameters.

The initial error model for the time-lapse inversions comprised two terms: an absolute error component of $0.1 \mathrm{mV}$ and a relative error component of $1 \%$ of the measured voltage. Errors in the current strength and electrode coordinates (hence geometric factors) were deemed minor compared to the voltage error. Moreover, for time-lapse inversions positional errors are constant and along with other systematic errors largely cancel out. In selecting the final inversion models used for further analysis, we picked for each time the models for which either the $\chi^{2}$ (i.e., the sum of squares of the data residuals normalized with the data errors divided by the number of data points) decrease of the data misfit at the subsequent iteration was $<0.1$, or $\lambda<1900$, corresponding to a maximum of five iterations: The final data misfits for the different time-lapse models varied between $0.4 \%$ and $2.4 \%$, with a median value of $1.6 \%$.

\section{ERT TIME-LAPSE INVERSION RESULTS}

We begin this section by showing vertical slices through the 3D $\delta \rho$ models that represent percent changes in resistivity relative to the background model at six chosen times. Next, we analyze the $\delta \rho$ time series extracted at different positions within the inversion volume. We then show temporal variations of $\delta \rho$ across several depth sections.

\section{Analysis of hydrologically relevant time frames}

To visualize the spatial and temporal variations in the ERT timelapse resistivity models, we extract six vertical slices between the boreholes in Figure 3a, three oriented north-south (NS1, NS2, and NS3) and three oriented east-west (EW1, EW2, and EW3). The $\delta \rho^{\mathrm{gw}}$ and $\delta h^{\mathrm{gw}}$ time series provided by loggers at $\sim 6.6-\mathrm{m}$ depth in boreholes P3 and P12 are shown for comparison in Figure 3b and 3c. Like $\delta \rho$, the $\delta \rho^{\mathrm{gw}}$ time series are percent changes relative to the $\rho^{\mathrm{gw}}$ values at the beginning of the time-lapse period, whereas $\delta h^{\mathrm{gw}}$ are absolute height differences. The six vertical slices at the six chosen time frames marked by green dashed lines in Figure $3 \mathrm{~b}$ and $3 \mathrm{c}$ are presented in Figure 3d-3i. The chosen time frames correspond to

I) Immediately after the beginning of $\delta \rho^{\mathrm{gw}}$ variations and approximately at the peak of the $\delta h^{\mathrm{gw}}$ time series

II) during an initial period of increasing $\delta \rho^{g w}$ (i.e., the first peak)

III) during a period of increasing $\delta \rho^{\mathrm{gw}}$, but when $\delta h^{\mathrm{gw}}$ has returned to its background level

IV) at a maximum of $\delta \rho^{\mathrm{gw}}$

V) near the beginning of the period of decreasing $\delta \rho^{\mathrm{gw}}$

VI) toward the end of the period of decreasing $\delta \rho^{\mathrm{gw}}$

Despite the large increase in groundwater height (Figure $3 \mathrm{c}$ ), the $\delta \rho$ model at time I (Figure $3 \mathrm{~d})$ reveals generally small $(<1 \%)$ variations, with a few regions along EW2 displaying more significant increases of up to $3 \%$. Less than a day later (Figure $3 \mathrm{e}$ ), $\delta \rho$ throughout most of the gravel aquifer displays increases on the order of $4 \%$ $5 \%$, very similar to the percent increases of $\delta \rho^{\mathrm{gw}}$ over the same time a)
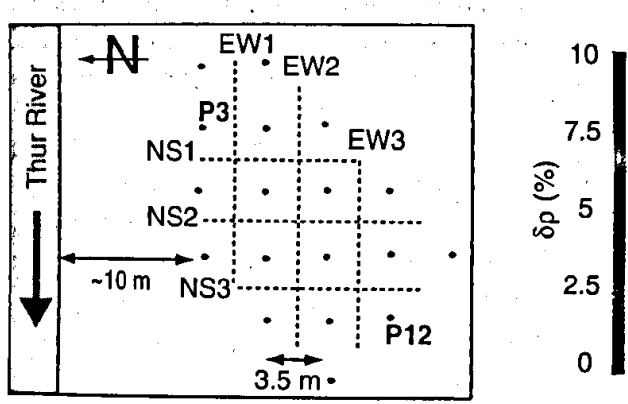

b)

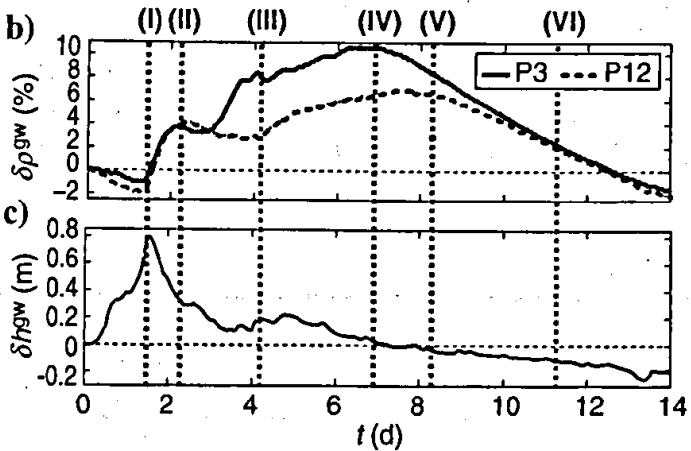

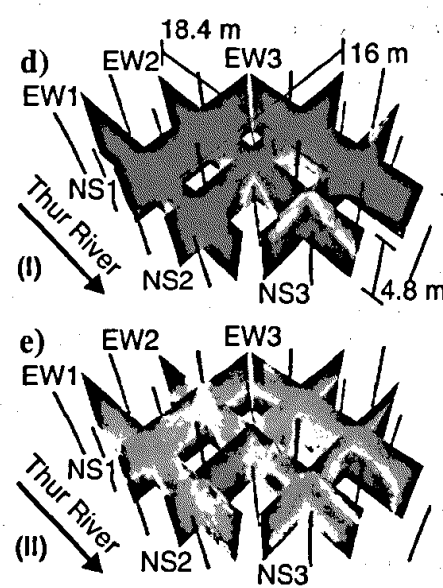
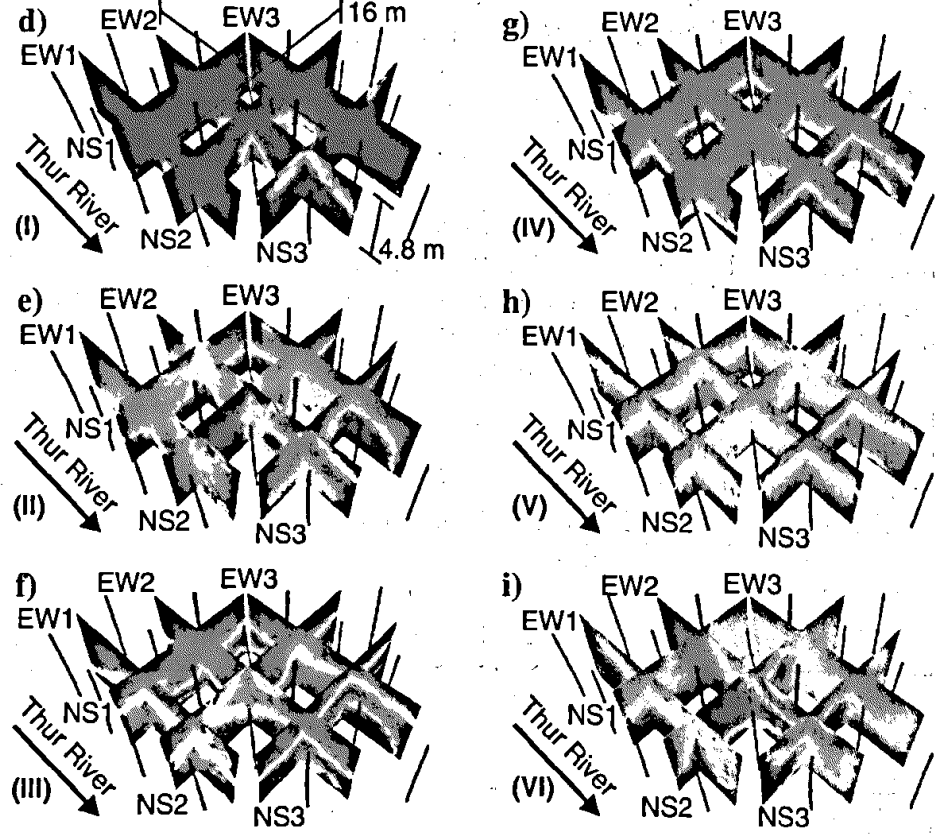

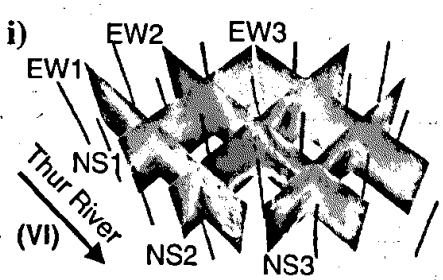

Figure 3. (a) Plan view of the boreholes (dots) and locations of six vertical slices EW1, EW2, EW3, NS1, NS2, and NS3 extracted from the time-lapse resistivity inversion models. Note the orientation of this diagram. (b) Time variations of groundwater resistivity $\delta \rho^{\mathrm{gw}}$ recorded by two point loggers at $\sim 6.6-\mathrm{m}$ depth. (c) Time variations in groundwater height $\delta h^{\mathrm{gw}}$. (d-i) Three-dimensional representations of the time-lapse bulk resistivity changes $\delta \rho$ (see locations in a) at the I-VI times marked by green dashed lines in (b) and (c). The lengths and depths of the vertical slices are shown in red in (d). 
period (Figure $3 \mathrm{~b}$ ). There is a volume in the western part of the $\delta \rho$ model with even stronger increases. The volume at the intersection of EW2 and NS2 and several zones at depth are practically unchanged. The uppermost meter of the saturated gravel at time III has high $\delta \rho$ values of up to $10 \%$ (Figure $3 f$ ), except at the intersection of EW2 and NS2. The highest values appear in the eastern part of the aquifer (NS1 and the eastern regions of EW1 and EW2), in which a thicker part of the aquifer (the upper two thirds) is sensing the propagating resistivity signal. The lowermost region furthest from the river shows no resistivity changes at this stage.

During the period of maximum $\delta \rho^{g w}$ (Figure $3 b$ ), the upper two thirds and most of the lower gravel aquifer show increased $\delta \rho$ values (Figure $3 \mathrm{~g}$ ). In the westem part of the study site far from the river (e.g., EW3), the effect is barely visible in the lower part of the aquifer. Notice that the NS2 slice contains strong variations throughout the aquifer thickness, whereas the neighboring slices NS1 and NS3 contain smaller variations in the lower part. At time V (Figure $3 \mathrm{~h}$ ), only the most shallow part of the gravel aquifer (upper meter) displays $\delta \rho$ values greater than $7 \%$. The highest values are seen at the western end of EW2. Finally, the zone between EW1 and EW2 is the first to approach the original background conditions (Figure 3i). The part of the aquifer more distant from the river (e.g., slice EW3) still shows $\delta \rho>2 \%$ through most of the aquifer thickness.

\section{Resistivity time series}

Figure 4a presents $\delta \rho$ time series for three depths at three locations within the gravel aquifer. These time series represent mean $\delta \rho$ values within $0.5-\mathrm{m}$-high cylinders of $1 \mathrm{~m}$ radius centered at the positions of interest. Locations 1 and 2 are situated in the east and west close to the river, and location 3 is in the west far from the river. For each of these locations, we display the time series at $4.6,6.6$, and $8.6 \mathrm{~m}$ depths, corresponding to the approximate depths of the groundwater resistivity loggers. The median $\delta \rho$ of the entire saturated aquifer is also plotted in Figure 4a.

Generally, the signal is more damped and the peak is delayed with increasing depth. Moreover, the time series are different for the two locations close to the river. Location 2 has a first peak approximately two days before the main peak. This first peak is almost absent in the time series at locations 1 and 3 . Finally, the arrival times of the maxima vary from four to eight days, with the earliest arrivals at shallow depths close to the river and the latest arrivals in the lower part of the aquifer most distant from the river.

\section{Temporal variations of $\delta \rho$ throughout the depth of the saturated gravel aquifer}

The spatial distribution of $\delta \rho$ time variations along vertical profiles at 16 different locations is shown in Figure 5. The magnitudes of $\delta \rho$ generally decrease with depth, but to differing degrees. High $\delta \rho$ values occur at locations $5,10,14$, and 16 along a zone that extends from the river toward the southwest. The vertical extent of large changes decreases along this zone. Locations 3 and 4 close to the river and locations 6 and 7 in the west also have relatively high $\delta \rho$ values in the upper part of the aquifer.

Figure 6 is the same as Figure 5, except that the time series have been normalized by assigning, at each location, values of zero and one to the background and peak magnitudes at each depth, respectively. These plots highlight temporal signal variability. They reveal that the peak traveltimes generally increase with depth and that delays with depth increase with distance from the river (see lines of locations that trend toward the southwest). This behavior is not found everywhere. The peak arrives first at intermediate aquifer depths at location 8, and it arrives first in the deeper parts at locations 2,3 , and 9. In addition, secondary peaks are clearly observed at locations 1 and 6.

\section{Comparison of ERT and groundwater resistivity time series}

A comparison of the $\delta \rho$ and the $\delta \rho^{g w}$ time series allows us to evaluate the extent to which the ERT time-lapse inversion models represent changes of groundwater resistivity and thereby image flow patterns. Figure 7 displays the $\delta \rho$ time series and corresponding $\delta \rho^{\mathrm{gw}}$ time series recorded on eleven loggers located along the main diagonal line of boreholes (P3, C2, C3, and P12 in Figure 1b) at three different depths. To pick the maxima of both time series, we first apply a low-pass 14-h moving average filter and then interpolate both suites of values to 155 equally spaced points over the 14 days of the inverted time series.

The general shapes and amplitudes of the $\delta \rho$ and the $\delta \rho^{g w}$ time series are alike in the upper and middle parts of the gravel aquifer, but differ somewhat in the lower part. In particular, the amplitudes of the $\delta \rho$ and the $\delta \rho^{\mathrm{gw}}$ maxima are comparable in Figure 7a-7h, but the $\delta \rho$ maxima are uniformly much smaller than the $\delta \rho^{\mathrm{gw}}$ maxima in Figure $7 \mathrm{i}-7 \mathrm{k}$. Most importantly, the arrival times of the $\delta \rho$ and the $\delta \rho^{\mathrm{gw}}$ maxima are similar in the upper and middle regions of
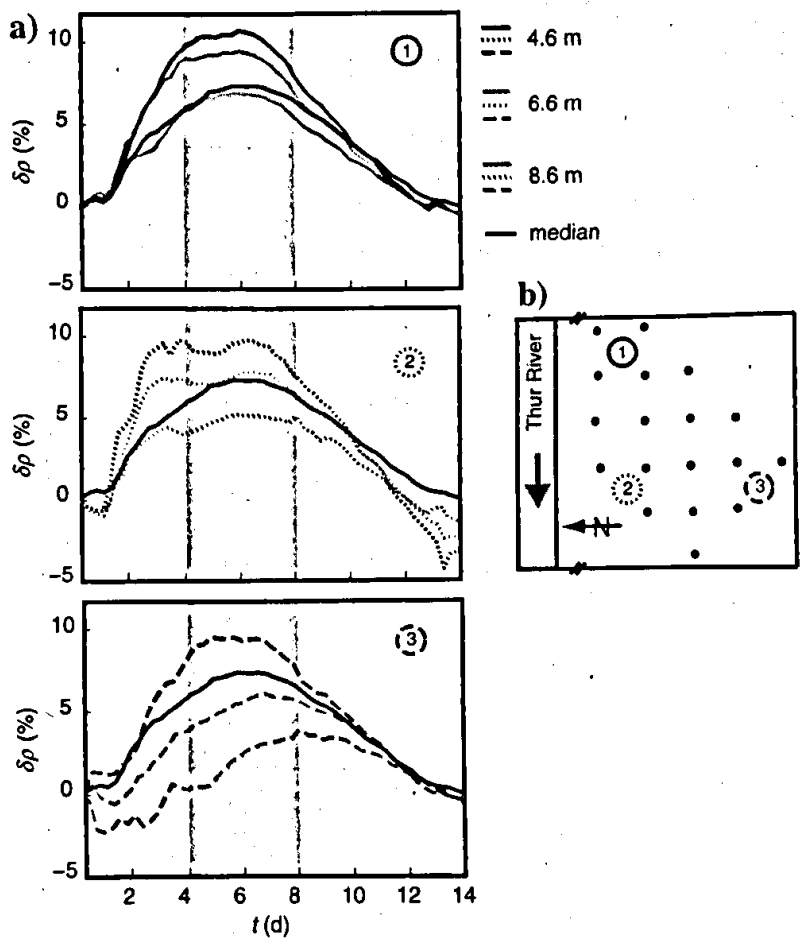

Figure 4. (a) Time-lapse bulk resistivity changes $\delta \dot{\rho}$ for three different depths at the three locations indicated in (b). Solid, dotted, and dashed lines correspond to locations 1,2 , and 3 , respectively. The black line shows the median $\delta \rho$ value for the entire saturated aquifer. The gray area highlights the temporal range of the peak arrivals. (b) Plan view of the three locations with respect to the river and the 18 boreholes. Note the orientation of this diagram. 
the aquifer (e.g., no arrival-time differences for Figure 7a, a maximum difference of 0.8 days for Figure $7 c$, and a mean difference of 0.3 days), whereas the $\delta \rho$ maxima are markedly delayed relative to the $\delta \rho^{\mathrm{gw}}$ maxima in deeper parts of the investigated volume (e.g., arrival times are delayed by $0.7-2.7$ days). The three loggers in each of the boreholes represented in Figure 7 were separated by rubber packers to decrease vertical flow of water from one level to another. Ideally, a single sensor should be used and tightly screened at the level of interest. We cannot exclude the possibility that some vertical mixing (upward or downward flow) has occurred and biased the logger measurements in the deeper parts of the aquifer. Furthermore, the sensitivity of the resistivity measurements to changes in the lower region of the aquifer is quite low for the acquisition geometry employed. This is caused by electrodes located only in the saturated gravel and by significant current channeling in the clay.

Background resistivities, traveltimes, and flow velocities

After demonstrating that the ERT-derived time series image infiltrating river water in the groundwater, we extracted time-lapse

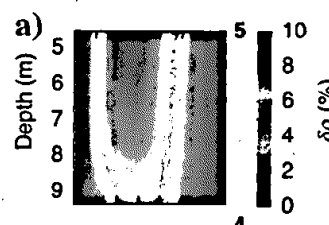

b)

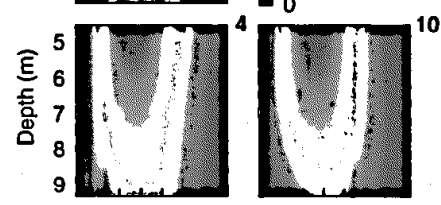
10
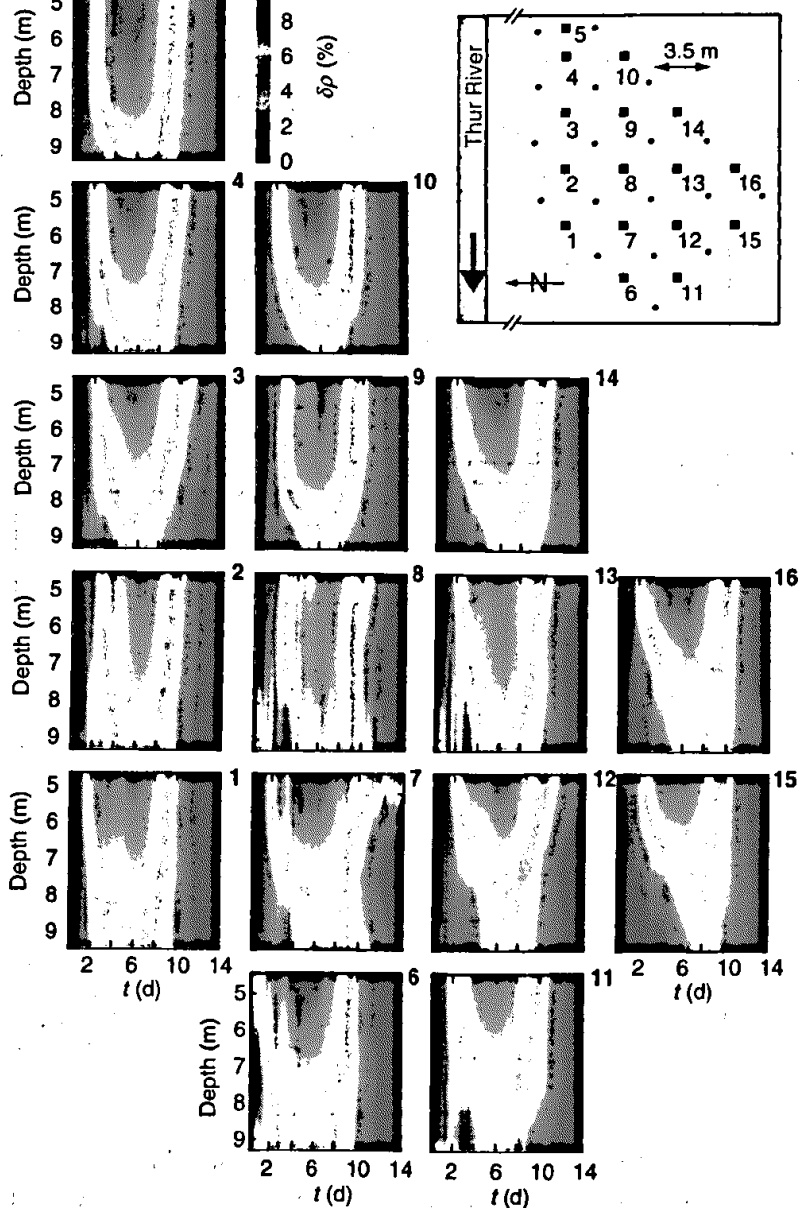

Figure 5. (a) Temporal variations of bulk resistivity $\delta \rho$ through the saturated aquifer at the 16 locations shown in (b). (b) Plan view of the locations with respect to the river. Note the orientation of this diagram. resistivities at points distributed on a grid (1-m spacing between nodes) at depths approximately corresponding to those of the borehole sensors (i.e., at $4.6,6.6$, and $8.6 \mathrm{~m}$ ). The resulting $\delta \rho$ time series were scaled by assigning zero and one to the background and maximum values, respectively, and the traveltimes were picked at amplitudes equal to 0.5. Background resistivities (i.e., those of the initial model used for the time-lapse inversions) are displayed in Figure $8 \mathrm{a}-8 \mathrm{c}$, whereas traveltimes relative to the start of the time-lapse period are presented in Figure 8d-8f.

Because we do not know the infiltration locations and flow paths of the infiltrating river water, we can only estimate a local velocity (i.e., speed and direction) at any desired point based on traveltimes within a specified distance of that point. A local velocity is calculated by assuming that the flow is approximately horizontal and can be described by a local planar front out to a distance of $3 \mathrm{~m}$ from the desired point. Based on arrival-time differences between the desired point and points within $3 \mathrm{~m}$ of it, local velocities at the three depth levels are estimated using a grid search procedure in which the speeds and horizontal flow directions are varied until the smallest misfit in a least-square sense is obtained between the computed and ERT-derived arrival-time differences. The resultant velocity

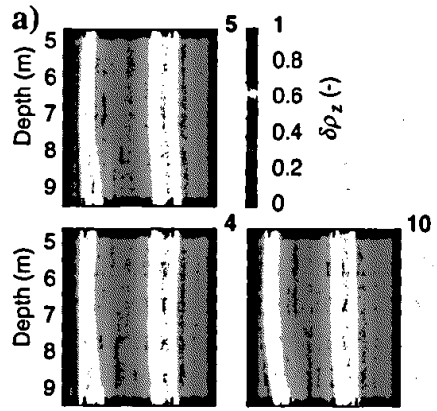

b)
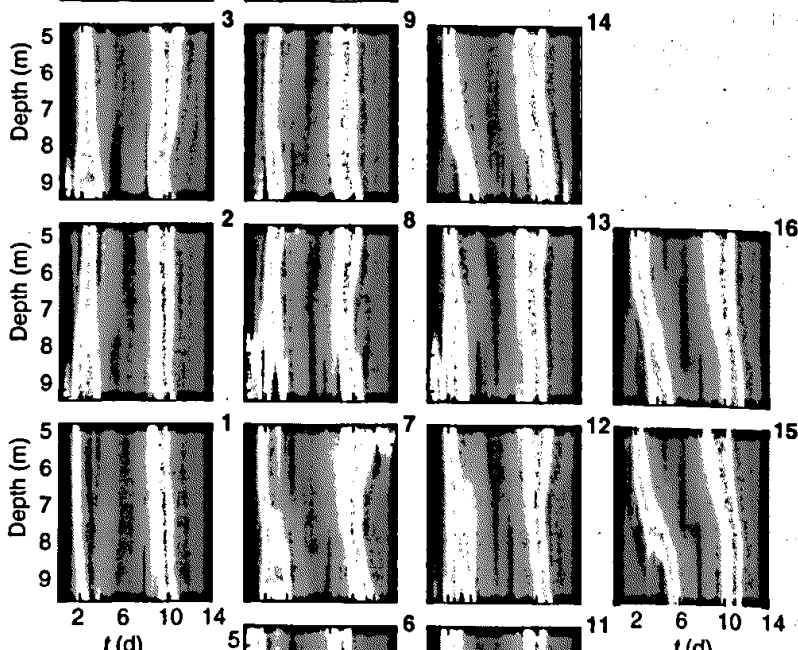

(d)

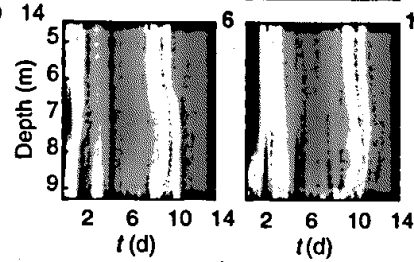

Figure 6. As for Figure 5, but with the temporal variations of bulk resistivity $\delta \rho$ normalized to a maximum value of one at each depth. 
estimate is only valid when the curvature of the changes in the timelapse resistivity model is negligible for the scales considered. Note that the approach is not mass conservative, such that nonphysical results may be obtained (e.g., accumulations of mass and apparent local flow directions that are much more variable than in reality). Furthermore, only the horizontal components of the flow velocities at each of the three levels are considered, with the vertical components ignored. Consequently, the local velocity estimates shown in Figure $8 \mathrm{~g}-8 \mathrm{i}$ should be viewed with some caution.

Natural gamma, gamma-gamma, and neutron-neutron logs recorded along the lengths of all boreholes (Coscia et al., 2011) provide important constraints on the interpretations of the background resistivities, traveltimes, and local velocities in Figure 8. In addition, electrical resistivity logs were recorded at ten locations between the boreholes using a direct-push system. The nuclear logs indicate that the low resistivities dominating the southem part of the 4.6-m-depth slice (Figure $8 \mathrm{a}$ ) correspond to a high-porosity zone that probably contains clean gravels with relatively high hydraulic conductivities. Low resistivities close to the river at $8.6-\mathrm{m}$ depth (Figure $8 \mathrm{c}$ ) are caused by clean fine sands, whereas low values in the south at this depth are caused by higher concentrations of clay/silt and associated higher surface conductivities. The uniformly high resistivities at intermediate depths (Figure 8b) are a consequence of low clay/silt content and relatively low porosities (Doetsch et al., 2010a; Coscia et al., 2011).

Traveltimes in Figure 8d-8f vary both laterally and vertically. They are generally shortest in the upper part of the aquifer. The most important features at $4.6-\mathrm{m}$ depth are the anomalously early arrivals in the south some distance from the river and the bull's eye of late arrivals near the center. The early arrivals in the south correlate with the prominent low resistivities in Figure 8a. The geophysical logs provide no direct information as to the source of the delays near the center. At $6.6-\mathrm{m}$ depth, the traveltimes are regular (compare Figure 8e with Figure 8d and 8f), increasing systematically with distance from the river. This regularity correlates with the uniform high resistivities in Figure $8 \mathrm{~b}$ and the associated low clay/silt content and low porosities in this depth range. The longest traveltimes in this depth slice occur in the southern corner of the site. It also appears that arrivals are somewhat earlier in the west than in the east. In the deeper part of the gravel aquifer at $8.6 \mathrm{~m}$ (Figure $8 \mathrm{f}$ ), the traveltimes are earliest close to the river in the west and increase with distance from the river toward the south and southwest.

The highest speeds appear to occur in the middle of the aquifer and the lowest speeds in the bottom part (Figure $8 \mathrm{~g}-8 \mathrm{i}$ ). The mean speeds and flow directions are $2.1 \mathrm{~m} / \mathrm{d}$ and $66^{\circ}$ (with respect to the river flow direction) at $4.6-\mathrm{m}$ depth, $5.2 \mathrm{~m} / \mathrm{d}$ and $67^{\circ}$ at $6.6-\mathrm{m}$ depth, and $1.6 \mathrm{~m} / \mathrm{d}$ and $53^{\circ}$ at $8.6-\mathrm{m}$ depth. Estimated flow speeds vary throughout the study volume from 1 to $25 \mathrm{~m} / \mathrm{d}$, with the strongest variations in the shallow ground $(4.6 \mathrm{~m})$. The local horizontal flow directions are variable too. Although the overall flow is directed southwest from the river, locally strong departures exist. For example, in all three depth intervals we observe elongated regions of higher speeds. At 4.6- $\mathrm{m}$ depth in the northwest region, we observe a nonphysical feature (a sink attracting water), which is a result of our velocity estimation approach (no mass conservation constraints and exclusion of vertical flow components). The low local speeds in this region correlate with the late arrivals at the same location. The low speeds in the bottom part of the aquifer are
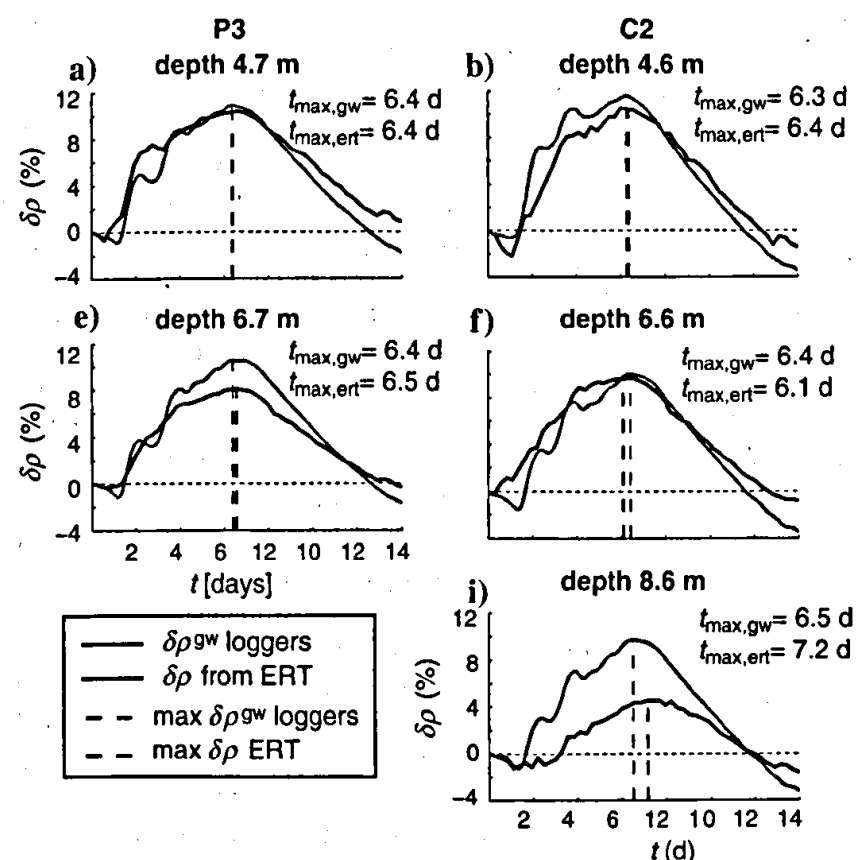

C2

b) depth $4.6 \mathrm{~m}$

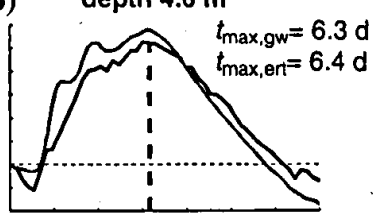

f) depth $6.6 \mathrm{~m}$
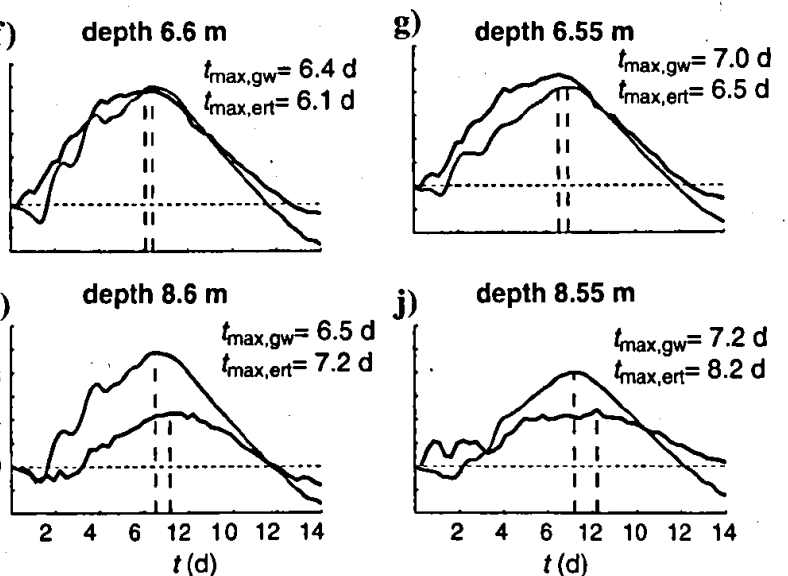

P12

c) depth $4.55 \mathrm{~m} \quad$ d)

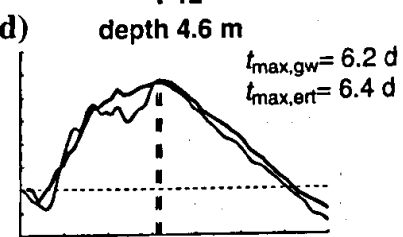

h) depth $6.6 \mathrm{~m}$

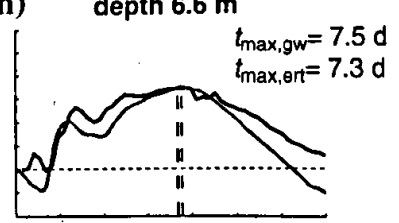

k) depth $8.6 \mathrm{~m}$

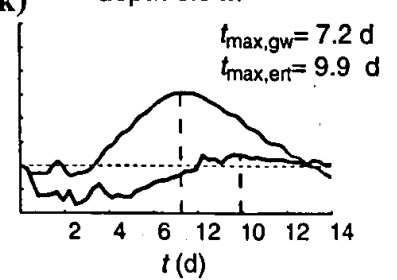

Figure 7. Time series of bulk resistivity $\delta \rho$ and groundwater resistivity $\delta \rho^{g w}$ throughout the inversion period. The plots are for the P3, C2, C3, and P12 boreholes (see locations in Figure 1b) and the depths at which the loggers are installed. The horizontal dashed black lines mark the background level. The $t_{\max , \log }$ and $t_{\max . e r t}$ are the times (in days since the beginning of the time-lapse inversion period) at which the maxima of $\delta \rho^{\mathrm{g} \omega}$ and $\delta \rho$ are observed. 
consistent with the late arrivals displayed in Figure 8f. High speeds are observed over the entire aquifer depth in the northeastern region of the investigated volume.

\section{DISCUSSION}

The fast responses of the groundwater height (head) to river height variations are a consequence of the rapid propagation of pressure pulses into the aquifer. It demonstrates that there is a good hydraulic connection between the river and groundwater. By comparison, the electrical resistivity signal caused by the rainfall-runoff event propagates much more slowly. The time-shift and transformation of this relatively abrupt river signal into a smooth groundwater signal reflects the solute transport processes in which we are interested.

We find the strongest electrical resistivity signal in the upper part of the aquifer and the weakest signals in the bottom part. We attribute this to a higher portion of freshly infiltrated river water in the upper part of the aquifer. As expected, traveltimes increase with increasing distance from the river throughout the study site, but this is especially pronounced in the bottom part of the aquifer. Moreover, this is the zone where the traveltimes are generally the longest. As the groundwater flow is generally directed toward the southwest, lower hydraulic conductivity in the bottom part of the aquifer is the likely cause of this difference in traveltime behavior.
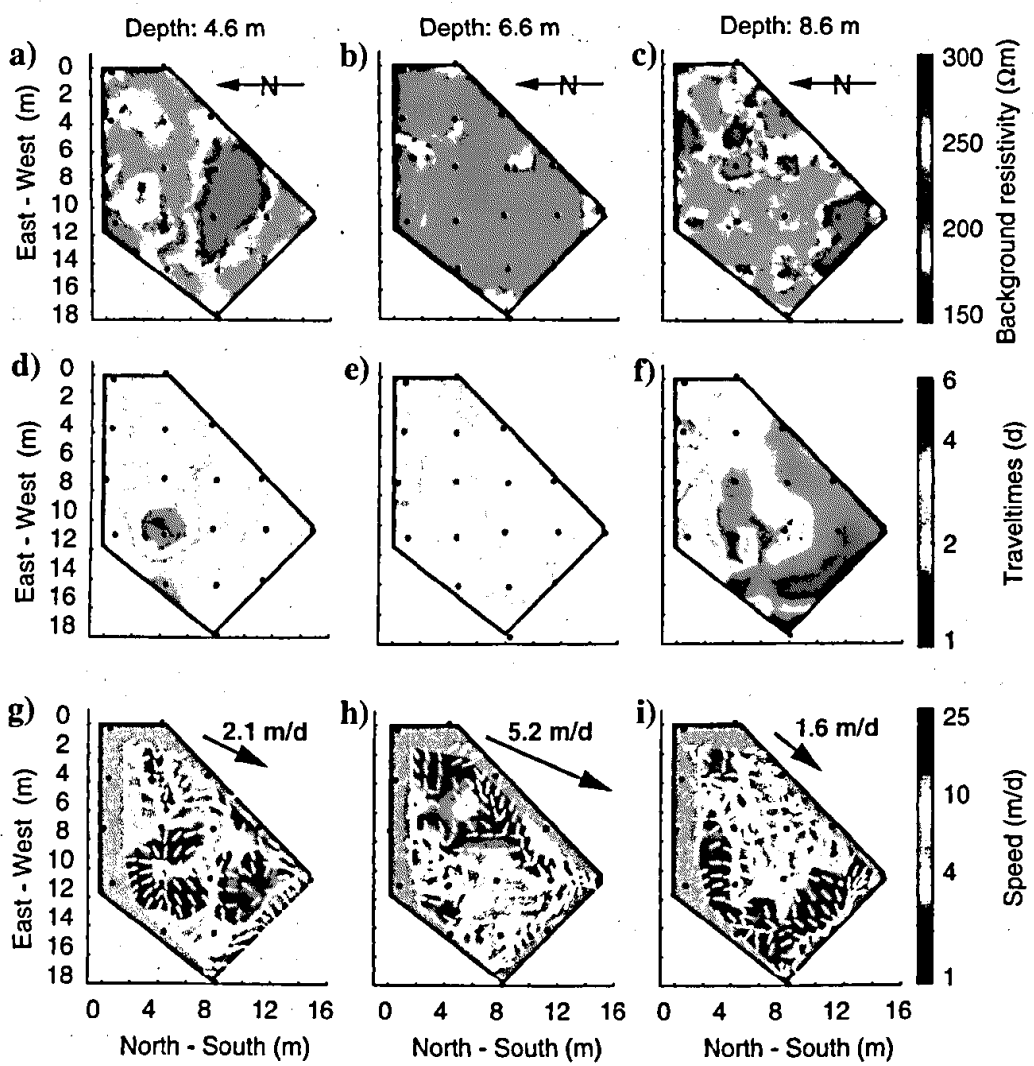

Figure 8. $(a, b, c)$ Horizontal slices showing background resistivities at depths of (a) $4.6 \mathrm{~m}$ (b) $6.6 \mathrm{~m}$, and (c) $8.6 \mathrm{~m}$. (d, e, f). Horizontal slices showing traveltimes of the $50 \%$ peak values of bulk resistivity at the same depths. $(\mathrm{g}, \mathrm{h}, \mathrm{i})$ Horizontal slices of the estimated local flow velocities at the same depths. Colors represent speeds and white arrows indicate directions.
Cirpka et al. (2007) calculate traveltime distributions from more than one year of river and borehole resistivity time-series. They also observed increasing traveltimes with increasing depth and increasing distance from the river. In contrast to their study, we have estimated traveltimes related to specific rainfall-runoff events, but the results of the two investigations are in general agreement. Unlike the Cirpka et al. (2007) study, we have assessed in detail the spatial distribution of arrival times and transport of river water infiltrating riparian groundwater. Beside the vertical differences of traveltimes and flow speeds, we could also determine horizontal differences covering the entire study volume, which would remain undetected using point measurements restricted to a few boreholes.

By comparing our results with background resistivities obtained during stable hydrological conditions, we can relate flow features to aquifer properties and heterogeneity. The flow speed results are generally consistent with our interpretation of background resistivities and traveltimes. The broad region of high local speeds at $4.6-\mathrm{m}$ depth (Figure $8 \mathrm{~g}$ ) is characterized by low resistivities (Figure 8a) and relatively early arrivals (Figure 8d), suggesting that this part of the gravel aquifer has a relatively higher hydraulic conductivity and could be a path of preferred or focused flow. The low local speeds near the center at this depth correlate with the late arrivals at the same location. We speculate that the preferential flow path diverts the early arriving river water away from this central location. The extensive high-speed zone at $6.6-\mathrm{m}$ depth in the eastern to southern parts of the aquifer (Figure $8 \mathrm{~h}$ ) could link to the broad high-speed zone at 4.6-m depth (Figure $8 \mathrm{~g}$ ). The relatively high and low local speeds in the east and west of Figure $8 \mathrm{~g}$ are not readily explained by the relatively late and early arrivals in Figure 8e at these respective locations. In the deeper part of the aquifer, late arrivals indicate the presence of sediments with lower hydraulic conductivity, possibly the clay/ silt-rich gravels represented by the low resistivities in the southem part of Figure 8c. The low speeds at this depth (Figure $8 \mathrm{i}$ ) are consistent with the late arrivals displayed in Figure $8 \mathrm{f}$ and our interpretation of low-permeability material in the lower parts of the aquifer.

The estimated mean speeds and flow directions $\left(2.1 \mathrm{~m} / \mathrm{s}\right.$ and $66^{\circ}$ at $4.6 \mathrm{~m}, 5.2 \mathrm{~m} / \mathrm{s}$ and $67^{\circ}$ at $6.6 \mathrm{~m}$, and $1.6 \mathrm{~m} / \mathrm{s}$ and $53^{\circ}$ at $8.6 \mathrm{~m}$ ) imply that the flow speeds and hydraulic conductivities are rather heterogeneous, but that the flow direction is relatively uniform throughout the depth range of the aquifer. The calculated flow directions and speeds are overall in agreement with the $40^{\circ}-45^{\circ}$ flow directions based on hydraulic head measurements during low flow conditions in the river.

In the upper and middle parts of the aquifer, the $\delta \rho$ and the $\delta \rho^{\mathrm{gw}}$ time series agree. In the bottom part, there are differences in the shape of the signal and the arrival times of the peaks. We suggest three possible explanations for the differences between the $\delta \rho$ and $\delta \rho^{\mathrm{gw}}$ time series in the lower parts of the gravel aquifer:

1) Vertical advective flow in the boreholes could smooth out and bias the signals sensed 
by the groundwater resistivity loggers (the ambient vertical flow in the open boreholes reaches rates as high as $61 / \mathrm{min}$ and it is unlikely that the packer system around the boreholes described by Coscia et al. (2011) prevents all of this upward flow).

2) Geophysical logs recorded in the boreholes suggest that some deeper parts of the aquifer have higher amounts of clay/silt and associated higher surface conductivities than the shallower regions (Coscia et al., 2011), such that changes in groundwater electrical resistivity translate to smaller relative changes in bulk resistivity in the deeper regions (i.e., a larger component of the bulk resistivity is not affected by the groundwater conditions). Surface conductivity effects are usually ignored in geophysical monitoring studies, but may influence transport property estimates (Singha et al., 2011). Although surface conductivity can partially account for the amplitude differences, it does not explain the time shifts other than indirectly through delays associated with flow through the lower permeable clays.

3) The $\delta \rho$ time series are volume-averaged estimates that account for resistivity variations in regions of low to high hydraulic conductivity, whereas the $\delta \rho^{\mathrm{gw}}$ time series are flux-averaged estimates that are mainly affected by transport processes in comparatively high-permeability zones.

We do not know the relative importance of the above effects at this stage of our investigation, but effects 2 and 3 likely play important roles. A more rigorous treatment of flow patterns would incorporate full 3D effects (vertical and horizontal flow) by using inverted resistivity data from multiple depth levels simultaneously rather than separately.

\section{CONCLUSIONS}

The main advantage of using 3D time-lapse crosshole ERT to image infiltrating river water after a rainfall-runoff event is the high resolution of the information provided throughout the investigated aquifer volume. Our results show that the heterogeneity of the gravel aquifer requires such detailed observations. High-discharge events like the studied ones are critical for pumping wells close to rivers due to higher groundwater-flow velocities and higher loads of contaminants and particles.

To obtain hydrologically relevant information from ERT apparent-resistivity data at the study site, it was necessary to correct for the significant effects of groundwater height and temperature variations. The corrected apparent resistivity data were time-lapse inverted using a versatile finite-element modeling and inversion scheme based on unstructured meshes. After important rainfallrunoff events, the resultant time series of percent bulk resistivity differences $\delta \rho$ in the inversion models were found to closely match percent groundwater resistivity differences $\delta \rho^{g w}$ measured in boreholes distributed throughout the study site; the trends and shapes of the two types of time series as well as the timing and amplitudes of the principal features were very similar in the upper and central parts of the aquifer. These results demonstrate that time-lapse variations of bulk resistivity caused by temporally changing properties of the infiltrating river water can be used to track arrival times and flow patterns in riparian groundwater systems.

For the rainfall-runoff event of our investigation, $\delta \rho$ changes from zero (background value) to $\sim 10 \%$ (one or more maxima) and then back to near zero throughout the $\sim 15 \times 10 \times 5 \mathrm{~m}$ studied volume in approximately 12 days. Variations in the timing and amplitude of $\delta \rho$ changes demonstrate that the river-water infiltration at our study site is unevenly distributed and that the aquifer is generally heterogeneous. The traveltimes of the $\delta \rho$ peak amplitudes vary by up to four days, depending on location and depth. They are earliest at shallow depths close to the river and latest at greater depths far from the river. Generally, the effect of river-water infiltration decreases with depth. Our investigation indicates that the highest portion of freshly infiltrated river water mostly flows through the shallow parts of the aquifer. Furthermore, they suggest that hydraulic conductivity decreases in the bottom part of the aquifer. To explain the distribution of the $\delta \rho$ values and the traveltimes and local speeds of the $\delta \rho$ peak amplitudes, a distinct shallow- to intermediate-depth zone of higher permeability and associated preferential flow paths is required within the eastern to southern regions of the study site. This zone is distinguished by lower resistivities, lower concentrations of clay/silt, and higher porosities than the surroundings.

\section{ACKNOWLEDGMENTS}

We thank our collaborators within RECORD, in particular Joseph Doetsch. We thank Thomas Günther for his continuous work in improving the Gimli software and Christoph Bärlocher for his essential contribution in building and maintaining the ERT monitoring installation. Funding for this study was provided by the Swiss National Science Foundation (SNF) and ETH's Competence Center for Environment and Sustainability (CCES). We are grateful to Andrew Binley for his constructive review of the manuscript. The revision has also benefitted from comments made by two anonymous reviewers.

\section{REFERENCES}

Acworth, R. I., and G. R. Dasey, 2003, Mapping of the hyporheic zone around a tidal creek using a combination of borehole logging, borehole electrical tomography and cross-creek electrical imaging, New South Wales, Australia: Hydrogeology Journal, 11, 368-377, doi: 10.1007/ s10040-003-0258-4.

Baumann, M., P. Jordan, E. Hoehn, and H. Geisser, 2009, Ein neues grundwassermodell für das Thurtal: Mitteilungen der Thurgausische Naturforschende Gesellschaft TNG.

Binley, A., and A. Kemna, 2005, DC resistivity and induced polarization methods, in Y. Rubin, and S. S. Hubbard, eds., Hydrogeophysics: Springer, 129-156.

BUWAL, 2004, Wegleitung grundwasserschutz, in Umwelt B. F., ed., Wald und Landschaft.

Cardenas, M. B., and M. S. Markowski, 2011, Geoelectrical imaging of hyporheic exchange and mixing of river water and groundwater in a large regulated river: Environmental Science \& Technology, 45, 1407-1411.

Cirpka, O. A., M. N. Fienen, M. Hofer, E. Hoehn, A. Tessarini, R. Kipfer, and P. K. Kitanidis, 2007, Analyzing bank filtration by deconvoluting time series of electric conductivity: Ground Water, 45, 318-328, doi: 10.1111/gwat.2007.45.issue-3.

Claerbout, J. F., and F. Muir, 1973, Robust modeling with erratic data: Geophysics, 38, 826-844, doi: 10.1190/1.1440378.

Constantz, J., 2008, Heat as a tracer to determine streambed water exchanges: Water Resources Research, 44, W00D10, doi: 10.1029/ 2008WR006996.

Coscia, I., S. A. Greenhalgh, N. Linde, J. Doetsch, L. Marescot, T. Günther, T. Vogt, and A. G. Green, 2011, 3D crosshole ERT for aquifer characterization and monitoring of infiltrating river water: Geophysics, 76, no. 2 G49-G59, doi: 10.1190/1.3553003.

Coscia, I., N. Linde, S. Greenhalgh, T. Günther, and A. Green, 2012 A filtering method to correct time-lapse 3D ERT data and improve imaging of natural aquifer dynamics: Joumal of Applied Geophysics, 80, 12-24, doi: 10.1016/j.jappgeo.2011.12.015.

Daily, W., A. Ramirez, D. LaBrecque, and J. Nitao, 1992, Electrical resistivity tomography of vadose water movement: Water Resources Research, 28, 1429-1442, doi: 10.1029/91WR03087.

Day-Lewis, F. D., J. W. Lane, Jr., J. M. Harris, and S. M. Gorelick, 2003, Time-lapse imaging of saline-tracer transport in fractured rock using difference-attenuation radar tomography: Water Resources Research, 39, 1290, doi: $10.1029 / 2002$ WR001722. 
de Franco, R., G. Biella, L. Tosi, P. Teatini, A. Lozej, B. Chiozzotto, M. Giada, F. Rizzetto, C. Claude, A. Mayer, V. Bassan, and G. Gasparetto-Stori, 2009, Monitoring the saltwater intrusion by time lapse electrical resistivity tomography: The Chioggia test site (Venice Lagoon, Italy): Journal of Applied Geophysics, 69, 117-130, doi: 10.1016/j.jappgeo 2009.08.004.

Diem, S., T. Vogt, and E. Hoehn, 2010, Spatial characterization of hydraulic conductivity in alluvial gravel-and-sand aquifers: $A$ comparison of methods: Grundwasser (in German), 15, 241-251.

Doetsch, J. A., I. Coscia, S. Greenhalgh, N. Linde, A. Green, and T. Günther, $2010 \mathrm{~b}$. The borehole-fluid effect in electrical resistivity imaging: Geophysics, 75, no. 4, F107-F114, doi: 10.1190/1.3467824

Doetsch, J. A., N. Linde, I. Coscia, S. A. Greenhalgh, and A. G. Green, $2010 \mathrm{a}$, Zonation for 3D aquifer characterization based on joint inversions of multimethod crosshole geophysical data: Geophysics, 75, no. 6, G53G64, doi: 10.1190/1.3496476.

Fàlgas, E., J. Ledo, A. Marcuello, and P. Queralt, 2009, Monitoring freshwater-seawater interface dynamics with audiomagnetotelluric data: Near Surface Geophysics, 7, 391-399.

Fleckenstein, J. H., R. G. Niswonger, and G. E. Fogg, 2006, River-aquifer interactions, geologic heterogeneity, and low-flow management: Ground Water, 44, 837-852, doi: 10.1111/gwat.2006.44.issue-6.

Günther, T., C. Rücker, and K. Spitzer, 2006, Three-dimensional modelling and inversion of DC resistivity data incorporating topography - II. Inversion: Geophysical Joumal International, 166, 506-517, doi: 10.1111 gii.2006.166. issue-2.

Hatch, M., T. Munday, and G. Heinson, 2010, A comparative study of inriver geophysical techniques to define variations in riverbed salt load and aid managing river salinization: Geophysics, 75, no. 4, WA135-WA147, doi: $10.1190 / 1.3475706$.

Hayley, K., L. R. Bentley, and A. Pidlisecky, 2010, Compensating for temperature variations in time-lapse electrical resistivity difference imaging: Geophysics, 75, no. 4, WA51-WA59, doi: 10.1190/1.3478208.

Hoehn, E., and O. A. Cirpka, 2006, Assessing residence times of hyporheic ground water in two alluvial flood plains of the Southern Alps using water temperature and tracers: Hydrology and Earth System Sciences, 10, 553563, doi: $10.5194 /$ hess-10-553-2006.

Hubbard, S. S., and Y. Rubin, 2000, Hydrogeological parameter estimation using geophysical data: A review of selected techniques: Journal of Contaminant Hydrology, 45, 3-34, doi: 10.1016/S0169-7722(00)00117-0.

Huggenberger, P., E. Hoehn, R. Beschta, and W. Woessner, 1998, Abiotic aspects of channels and floodplains in riparian ecology: Freshwater Biology, 40, 407-425, doi: 10.1046/j.1365-2427.1998.00371.x.

ISO7888, International Norm, 1985, Water quality - Determination of electrical conductivity, http://www.iso.org/iso/iso_catalogue/.

Kalbus, E., F. Reinstorf, and M. Schirmer, 2006, Measuring methods for groundwater - Surface water interactions: A review: Hydrology and Earth System Sciences, 10, 873-887, doi: 10.5194/hess-10-873-2006.

Karaoulis, M. C., J. H. Kim, and P. I. Tsourlos, 2011, 4D active time-constrained inversion: Journal of Applied Geophysics, 73, 25-34, doi: $10.1016 / \mathrm{j}$.jappgeo.2010.11.002.

Kim, J. H., M. J. Yi, S. G. Park, and J. G. Kim, 2009, 4D inversion of DC resistivity monitoring data acquired over a dynamically changing earth model: Journal of Applied Geophysics, 68, 522-532, doi: $10.1016 \mathrm{I}$ j.jappgeo.2009.03.002.

Kirkegaard, C., T. O. Sonnenborg, E. Auken, and F. Jorgensen, 2011, Salinity distribution in heterogeneous coastal aquifers mapped by airborne electromagnetics: Vadose Zone Joumal, 10, 125-135.

Klotzsche, A., J. van der Kruk, G. A. Meles, J. A. Doetsch, H. Maurer, and N. Linde, 2010, Full-waveform inversion of crosshole ground penetrating radar data to characterize a gravel aquifer close to the Thur River, Switzerland: Near Surface Geophysics, 8, 635-649.

LaBreque, D. J., and X. Yang, 2001, Difference inversion of ERT data: A fast inversion method for 3D in situ monitoring: Journal of Environmental and Engineering Geophysics, 6, 83-89, doi: 10.4133/JEEG6.2.83.

Lesmes, D. P., and S. P. Friedman, 2005, Relationships between the electrical and hydrogeological properties of rocks and soils, in Rubin, Y., and S. S. Hubbard, eds., Hydrogeophysics: Springer, 87-128.

Naef, H., and S. Frank, 2009, Neue erkenntnisse zur entstehung und zum aufbaudes Thurtaler gnundwassenträgers zwischen Bürgelen und niedemeunforn. In ein neues grundwassermodell für das Thurtal, P. J. M. Baumann, E. Hoehn, and H. Geisser, eds. Mitteilungen der ThurgausischeNaturforschende Gesellschaft TNG.
Nenna, V., A. Pidlisecky, and R. Knight, 2011, Application of an extended Kalman filter approach to inversion of time-lapse electrical resistivity imaging data for monitoring recharge: Water Resources Research, 47, W10525, doi: $10.1029 / 2010$ WR010120.

Nguyen, F., A. Kemna, A. Antonsson, P. Engesgaard, O. Kuras, R. Ogilvy, J. Gisbert, S. Jorreto, and A. Pulido-Bosch, 2009, Characterization of seawater intrusion using 2D electrical imaging: Near Surface Geophysics, 7, 377-390.

Nyquist, J. E., P. A. Freyer, and L. Toran, 2008, Stream bottom resistivity tomography to map ground water discharge: Ground Water, 46, 561-569. doi: 10.1111 gwat.2008.46.issue-4.

Ogilvy, R. D., P. I. Meldrum, O. Kuras, P. B. Wilkinson, J. E. Chambers, M Sen, A. Pulido-Bosch, J. Gisbert, S. Jorreto, I. Frances, and P. Tsourlos, 2009, Automated monitoring of coastal aquifers with electrical resistivity tomography: Near Surface Geophysics, 7, 367-375.

Ranalli, A. J., and D. L. Macalady, 2010, The importance of the riparian zone and in-stream processes in nitrate attenuation in undisturbed and agricultural watersheds - A review of the scientific literature: Joumal of Hydrology, 389, 406-415, doi: 10.1016/j.jhydrol.2010.05.045.

Rein, A., R. Hoffmann, and P. Dietrich, 2004, Influence of natural timedependent variations of electrical conductivity on DC resistivity measurements: Joumal of Hydrology, 285, 215-232, doi: 10.1016/j.jhydrol.2003 .08 .015 .

Rücker, C., T. Günther, and K. Spitzer, 2006, Three-dimensional modelling and inversion of DC resistivity data incorporating topography - I. Modelling: Geophysical Journal International, 166, 495-505, doi: $10.1111 / \mathrm{gji}$ .2006.166.issue-2.

Schwarzenbach, R. P., and J. Westall, 1981, Transport of non-polar organiccompounds from surface-water to groundwater - Laboratory sorption studies: Environmental Science \& Technology, 15, 1360-1367.

Sheets, R. A., R. A. Darner, and B. L. Whitteberry, 2002, Lag times of bank filtration at a well field, Cincinnati, Ohio, USA: Journal of Hydrology, 266, 162-174, doi: 10.1016/S0022-1694(02)00164-6.

Singha, K., L. Li, F. D. Day-Lewis, and A. B. Regberg, 2011, Quantifying solute transport processes: Are chemically "conservative" tracers electrically conservative?: Geophysics, 76, no. 1, F53-F63, doi: 10.1190/1.3511356.

Singha, K., A. Pidlisecky, F. D. Day-Lewis, and M. N. Gooseff, 2008, Electrical characterization of non-Fickian transport in groundwater and hyporheic systems: Water Resources Research, 44, W00D0, doi: 10.1029/2008WR007048.

Slater, L. D., D. Ntarlagiannis, F. D. Day-Lewis, K. Mwakanyamale, R. J. Versteeg, A. Ward, C. Strickland, C. D. Johnson, and J. W. Lane, 2010 Use of electrical imaging and distributed temperature sensing methods to characterize surface water-groundwater exchange regulating uranium transport at the Hanford 300 Area, Washington: Water Resources Research, 46, W10533, doi: 10.1029/2010WR009110.

Slater, L. D., and S. K. Sandberg, 2000, Resistivity and induced polarization monitoring of salt transport under natural hydraulic gradients: Geophysics, 65, 408-420, doi: 10.1190/1.1444735.

SN670008A, 1997, Identifikation der Inckergesteine, labormethode, Vereinigung, and S. Strassenfachleute, eds.

Triska. F. J., J. H. Duff, and R. J. Avanzino, 1993, The role of water exchange between a stream channel and its hyporheic zone in nitrogen cycling at the terrestrial aquatic interface: Hydrobiologia, 251, 167184, doi: $10.1007 / \mathrm{BF} 00007177$.

Viezzoli, A., L. Tosi, P. Teatini, and S. Silvestri, 2010, Surface water-groundwater exchange in transitional coastal environments by airborne electromagnetics: The Venice Lagoon example: Geophysical Research Letters, 37. L01402, doi: 10.1029/2009GL041572.

Vogt, T., E. Hoehn, P. Schneider, A. Freund, M. Schirmer, and O. A. Cirpka, 2010, Fluctuations of electrical conductivity as a natural tracer for bank filtration in a losing stream: Advances in Water Resources, 33, 12961308, doi: $10.1016 /$ j.advwatres.2010.02.007.

Ward, A., M. N. Gooseff, and K. Singha, 2010, Characterizing hyporheic transport processes - Interpretation of electrical geophysical data in coupled stream-hyporheic zone systems during solute tracer studies: Advances in Water Resources, 33, 1320-1330, doi: 10.1016/j.advwatres .2010 .05 .008 .

Yeh, T. C. J., C. H. Lee, K. C. Hsu, W. A. Illman, W. Barrash, X. Cai, J. Daniels, E. Sudicky, L. Wan, G. M. Li, and C. L. Winter, 2008, A view toward the future of subsurface characterization: CAT scanning groundwater basins: Water Resources Research, 44, W03301, doi: 10.1029/ 2007 WR 006375 . 